\title{
Ideologies of time: How elite corporate actors engage the future
}

\author{
Christina Berg Johansen (Copenhagen Business School) \\ \& \\ Christian De Cock (University of Essex)
}

\begin{abstract}
Our paper deals with how elite corporate actors in a Western capitalist-democratic society conceive of and prepare for the future. Paying attention to how senior officers of ten important Danish companies make sense of the future will help us to identify how particular temporal narratives are ideologically marked. This ideological dimension offers a common sense frame that is structured around a perceived inevitability of capitalism, a market economy as the basic organizational structure of the social and economic order, and an assumption of confident access to the future. Managers envisage their organization's future and make plans for organizational action in a space where 'business as usual' reigns, and there is little engagement with the future as fundamentally open; as a time-yet-to-come. In using a conceptual lens inspired by the work of Fredric Jameson, we first explore the details of this presentism and a particular colonization of the future, and then linger over small disruptions in the narratives of our interviewees which point to what escapes or jars their common sense frame, explore the implicit meanings they assign to their agency, and also find clues and traces of temporal actions and strategies in their narratives that point to a subtly different engagement with time.
\end{abstract}

Keywords: future, time, Jameson, ideology, history, sustainability, corporate strategy 


\section{Introduction}

The notion of how we engage with the future has become of increasing concern in our field and the social sciences more generally as we are rapidly moving away from industrial capitalism as we understood it in the $20^{\text {th }}$ century (Frase, 2016; Kunkel, 2014). Such concerns revolve around the critical role corporations play in creating and responding to our climate changed future (Ghosh, 2016; Nyberg and Wright, 2016; Urry, 2008; Wright et al., 2013) and the broader deep indeterminacy that inheres in the present condition of the capitalist political economy (Haraway, 2016; Morton, 2013; Streeck, 2016; Wallerstein et al., 2013). What these many scholars share is an acute awareness that that the current path of economic growth and consumerism is unsustainable and that Western societies will have to come to terms "with ways of living which differ radically from those that they have become accustomed to" (Gosling and Case, 2013: 708). Yet, the short-term economic positioning so ingrained in late capitalism has glossed over any need for inter-temporal tradeoffs (Bansal and DesJardine, 2014), proffering a simple win-win discourse (Crane et al., 2014) where the future simply becomes an opportunity for identifying new business models, developing new technologies and conquering new markets (Painter-Morland and ten Bos, 2016; Wittneben et al., 2012) - and it is this business-oriented frame of reference which seems to dominate our quotidian relation to our future (Klein, 2014). Gayá and Phillips (2016: 807) suggest that "assumptions of the future as immutable" are as prevalent in 
organizational research as in popular management discourse and evoke "futures in which existing hegemonic discourses, structures and patterns of behaviour are largely replicated or even intensified". In other words, there seems to be something profoundly ideological about how we relate to the future and time more generally, and we therefore need to ask ourselves how ideology functions in our current historical moment. How does the interplay between a legitimizing set of beliefs and material practices determine how our attentions become trained and selectively cast (Stoler, 2010)? What are the frames - consisting of both social imaginaries and corporate configurations - that "sort out those parts of the present that might lead to the future" (Tsing, 2015: 20), and what drops out of these frames as negligible? It is the aim of our study to address these questions through a theoretically informed empirical analysis of the narratives of senior officers belonging to a cross-section of globally important Danish companies.

In the following theoretical section we will first introduce our particular take on ideology inspired by Fredric Jameson's work, which leads to Jameson's concern about our incapacity to integrate a future of time in our socio-economic analyses. His apprehensions about our "contemporary imprisonment in the present" (Jameson, 2015: 120) are then linked to the acceleration in our spatial, material and social relations in which time becomes constant change (Rosa, 2013) and an individualizing imaginary in which the idea of collective experience is receding fast (Ghosh, 2016). In concluding our theoretical section we then connect Jameson's central question - 'How to open up 
the present to more than its own repetition?' - to eco-philosophical conceptualisations of agency (Haraway, 2016; Moore, 2015; Morton 2013) that aim to extend the "actantial field" (Jameson, 2009: 579) and bring to light aspects of the world where the seeds of the future are immanent in, but not bounded by, the present.

\section{Of ideology and the future}

In exploring the notion of ideology we will rely on Fredric Jameson's writings, and in particular his two-volume The Ideologies of Theory $(1988,1989)$ from which we have borrowed the title for this article. For Jameson (2016b: 311) ideology is how we "designate the situation-specificity of all thought and all positions". Ideology in its formal sense refers to a whole system of legitimizing beliefs and practices, the "complicated machinery through which hitherto we have alone learned to see reality" (Jameson, 1989: 117). Given that everything we think is always "slanted and conditioned by the situation in which we are formed" (Jameson, 2016b: 311), the first step in becoming aware of ideology is "to take an inventory of the things excluded from this ideology, and to make ourselves more acutely aware of the kinds of things rejected by the machine" (Jameson, 1989: 117). Jameson already explored in the 1970s and 1980s how the practices of consumption and consumerism - commodity reification in a Marxist vocabulary (e.g. Jameson, 2016: 68) - are enough "to reproduce and legitimate the system, no matter what 'ideology' you happen to be committed to... the immanent 
practices of daily life now occupy the functional position of 'ideology' in its other larger systemic sense" (Jameson, 1989: 55 - emphasis added). More recently, Srnicek and Williams (2015) argued that neoliberalism has come to shape not only elite opinions and beliefs, but also the material fabric of everyday life itself. Fisher (2009: 16) referred in this context to 'capitalist realism' which functions like a "pervasive atmosphere... acting as a kind of invisible barrier constraining thought and action".

One particular effect of our ideological predicament is that it serves to fragment time into a series of perpetual presents (Kunkel, 2014). In our engagements with the future, scientific and technological advances have become taken for granted and are less connoted with new societal structures, ecological changes or political systems than with a sense of narcissistic fascination with human innovation capacity (Urry, 2008). Progress thus comes to mean little more than "an attempt to colonize the future, to draw the unforeseeable back into tangible realities, in which one can invest and on which one can bank, very much in the spirit of stockmarket 'futures"' (Jameson, 2005: 228). The neutralized future of contemporary capitalism has lost its potential as a space in which alternative societies and organizations can be realised, or as a utopian vision that makes us reflect on the dysfunctionalities of the present; it is built on conventions of rational agency (Joas, 1996) which drastically circumscribe our abilities of description and imagination. Fisher (2009) considers Jameson's identification and analysis of the future as "a monotonous repetition of what is already there" (Jameson, 2003: 76) as one of his 
most important contributions, whilst pointing out that some of the processes Jameson described several decades ago in works like The Ideologies of Theory have become "so aggravated and chronic that... what we are dealing with now is a deeper, far more pervasive sense of exhaustion""1 (Fisher, 2009: 7).

Having lost the idea of the future as different from the present, what we seem to be left with is an increased speed and efficacy in our societal developments - spatial relations transformed by the acceleration of transportation, social relations by the acceleration of communication, and material relations by the acceleration of production (Rosa, 2013). Time becomes change; a constant liquid (Bauman, 2000) that dissolves firmly established, historically and geographically stable social aggregates in flows beyond international control (Rosa, 2013). This kind of change is thus "no longer perceived as a transformation of fixed structures, but instead as a fundamental and potentially chaotic indeterminacy" (Rosa 2013:109). The idealized free market is the perfect flow of indeterminacy to which organizations must adapt. At one and the same time, capitalism's liquid present becomes wholly open and always changing, as well as

\footnotetext{
${ }^{1}$ This sentiment is not confined to publications from the Left. A recent Financial Times article (Wolf, 2016) has a revealing cartoon based on the iconic image of the workers eating lunch perched on a beam of the then under construction RCA building, 69 floors above Manhattan (taken on September 20, 1932); only in this particular representation they are all slumped and come across as utterly exhausted. Wolf ends the article on a pessimistic note: "We must not assume an easy return to the long-lost era of dynamism. Meanwhile, the maldistribution of the gains from what growth we have is a growing challenge. These are harsh times."
} 
constantly determined by a need to handle time in a linear way to make it feed into accelerated production. Inevitably managerial agency will be affected under these conditions where 'the new' looms as fleeting and un-navigable. One of the outcomes is an organizational context beset with unintended and unanticipated consequences of apparently very purposeful, but in their effects increasingly unpredictable, managerial actions (Streeck, 2016).

There resides an interesting condition in the 'un-navigable' new: the idea that the capacity of the market to generate new technological solutions to human issues will somehow take care of us. Geo-engineering, stem cell research or nano-technology all offer ideas of how to live smarter on this earth. But they do not make us dream of better lives for our grandchildren, or of more just societies. In this sense, contemporary capitalism seems to have lost the "potential utopian surplus" of earlier ages such as the late $18^{\text {th }}$ century 'Neuzeit', where the future was coupled to the "expectation that scientific inventions and discoveries would bring about a new world" (Koselleck 2004: 269 ), or the utopianism of modernism during the first three decades of the $20^{\text {th }}$ century with its "visionary teleologies... of radical transcendences of the past and of tradition, the emergence of new forms of perception and of experience - even, in avant-garde politics, the emergence of new kinds of human being" (Jameson, 2015: 124). Though the dynamism of these times built on appropriations of Nature and human labour (Moore, 2015) and has been both destructive and anthropocentric in its visions for a 
better world, it was ripe with ideals of making leaps of improvement in society. Modernism was concerned with introducing a rupture between present and past with the future being potentially different from, and better than the present. Technological and social revolutions were very much intertwined and these experiments to "channel history" and cultivate anticipations of a future society, "gave credence to the idea that anything was achievable in a time of rapid modernisation" (Srnicek and Williams, 2015: 137).

This collective excitement and belief that capitalist growth would create new and better worlds, has all but vanished. This has not been a random process but the outcome of a profoundly ideological period we have lived through; Streeck (2016: 13) evocatively writes of "the pulverization of collective agency in the course of the neoliberal revolution" in this context. While the processes that join the personal to the aggregate and the aggregate to the personal are withering away (Powers, 2005), individual citizens seem paralyzed, engulfed by a “deep pessimism” (Scrnicek and Williams, 2015:46) while focusing on their own survival and economic freedoms in precarious peripheries and central institutions alike (Ho, 2009; Tsing, 2015). The net result is "a deadlocked public sphere, with the actual exercise of power being relegated to the interlocking complex of corporations and institutions of governance (Ghosh, 2016: 131). 
But perhaps our notions of 'the collective' are themselves fraught with historicist conceptions of (human) agency in the stories of capitalism, as ideals of deliberate, direction-setting movements of a certain size and shape. If we turn our attention to what goes on in the detailed landscapes and ruins of capitalism, we may explore how "the past carries with it a secret index by which it is referred to redemption", as Walter Benjamin (1999) contended in the second of his theses on the philosophy of history. What is at stake in such a Benjaminian concept of the present as a living dialectic of past and future, is "the art of experiencing the present as waking world", where we experience time as "now time" - Jetztzeit (Eiland and Jennings, 2014: 43), and where we may find new types of agency that are local, experimental and co-dependent and in which the present is heterogenous and full of unpredictable actors and activities (Tsing, 2015).

The central quest then becomes to explore the present and find traces and places where it reveals more than its own repetition. What is at issue here is the actually existing tendencies and affordances of our world today, which may be experienced only in a yet ambivalent and cloudy form. It involves a reconceptualization and cognitive remapping of the actantial field: the creation or rediscovery of "actants, agents, narrative characters, in a far more inclusive narrative about late capitalism... produced for our collective and political discovery and recognition" (Jameson, 2009: 582). To understand this new sense of collective production, Morton (2013) argues that human beings must reflect 
deeply on their co-existence with nonhumans and recognize their profound infiltration by what he calls 'hyperobjects' which are defined in part by their stickiness, their ever firmer adherence to our lives ${ }^{2}$ (Ghosh, 2016), and which are widely distributed in time and space. Morton's work is part of what may be called a postmodern eco-philosophical approach to agency (Moore, 2015) in which a 'vital materiality’ opens up a nonteleological future that embraces "more intelligent and sustainable engagements with vibrant matters and lively things" (Bennett, 2010: viii). It posits an asymmetry between action and reflection, in which modernity's constant "injunctions to act cripple genuine action" (Morton 2013:92). Such genuine action requires 'attunement' to the larger objects and temporalities we are part of, as well as to the myriad (micro)organisms that make and sustain us in earthly 'sympoiesis' (Haraway, 2016), creating, in the words of Jameson (2009: 416), "a more receptive and interpretive stance in which... we may detect the allegorical stirrings of a different state of things" 3 .

In what follows we aim to demonstrate how the theoretical concerns and issues around the capitalist ideology of time we have outlined so far play out when people charged

\footnotetext{
${ }^{2}$ Morton (2013) defines them thus: "Hyperobjects are not simply mental (or otherwise ideal) constructs, but are real entities whose primordial reality is withdrawn from humans... they seem to force something on us, something that affects some core ideas of what it means to exist (p.15)... We never see the hyperobject directly. We infer it from graphs, instruments, tracks in a diffusion cloud chamber, sunburn, radiation sickness..." (p.161).

${ }^{3}$ In The Ideologies of Theory Jameson already attempted to sketch out a Marx-inspired worldview "for which those multiple dimensions and temporalities we sometimes crudely call the political, the history of forms, the dynamics of desire, the class texture of the social, the originality of the act, and geological rhythms of human history, all unimaginably coexist". (Jameson, 1988: xxix)
} 
with extensive and significant management responsibilities are asked to imagine the future. Relations between capitalist organizing and temporality are often researched from philosophical and/or macro-empirical perspectives, but we know less about their effects on specific strategic deliberations and individual managerial decisions. We are interested therefore in managers' well-rehearsed convictions and credulities about their organizations. Whilst giving due credit to the elasticity and receptivity of our respondents' outlook, our focus will be very much on "locating the ultimate structural limits of that outlook and coming to terms with its negation, with what it cannot absorb" (Jameson, 1989: 117). Upon locating these limits, we turn our attention to certain exceptions and particular reflections that differed significantly from the prevailing future orientation of our respondents; the moments when "epistemic habits fail to do their work, in which, even for a brief moment, what once seemed 'normal' and 'obvious' is open to reflection and no longer looks the same" (Stoler, 2016: 22). We ask ourselves the question whether and how the 'new' types of agency advanced by eco-philosophical thought may exist in the deepest part of the machine itself, as opposed to only outside it and in its ruins; exploring possible traces of interactive, collective, material 'attunements' in mundane managerial strategizing. Our critical aim here is thus not 'fault finding' and judgement of our interviewees, but an understanding of how particular conceptual habits and structural restrictions make them move along - and occasionally awkwardly against - the grain. 


\section{Sources and method}

Our study is based on small sample interview data from ten elite actors in the Danish corporate world, mainly CEO level or Executive Management members. This elite level of managers is often overlooked in social theory, partly because the elite is more challenging to reach than other less influential organizational actors (Savage and Williams, 2008). Our cardinal interest in researching these elite actors was their position as spokespersons for their corporation, mapping their organizations" "grids of intelligibility" (Stoler, 2010: 37) that make certain ways of dealing with the future obvious and acceptable whilst considering others discordant and strange; the "kinds of things rejected by the machine" in Jameson's (1989:117) words. We see these top managers as inscribed into the webs of practice and experience that create conceptions of the future in today's corporate capitalism, whilst acknowledging there exists a tension between "the bodiless being of the institution and the corporeal being which gives it a voice" (Boltanski, 2011: 87). Whilst they are spokespersons for their institutions, and without exception would be considered to be powerful organizational actors, we also found our interviewees to be intelligent and articulate agents endowed with extensive critical capacity. We were thus interested in how these powerful

\footnotetext{
${ }^{4}$ Boltanski (2011: 85) is very much aware of the tension created by flesh-and-blood beings having to present themselves in their "institutional modality" and convey the will of this "bodiless being" that is the corporation. He elaborates: "This tension is not ignored by spokespersons. There does indeed exist a way for them to seek to protect themselves against the denaturalizing effect of the institutional performance... by adjusting to the situations as if they were plunged into them as ordinary individuals" (p.93).
} 
individuals think and sometimes find themselves having difficulty thinking (for example when asked about the distant future); allowing us to linger over the sudden disruptions in their mostly coherent and articulate narratives. We were also drawn to particular acts of ignoring (rather than ignorance). Such "conditions of disregard" (Stoler, 2010: 256) - why it makes sense for our interviewees not to concern themselves - are located in the implicit meanings they assign to their own acts and agency.

The corporations that the managers represent all have an international presence, sophisticated strategy processes and future ambitions, and are generally recognized as highly legitimate actors with a strong business model. Most of the companies are very large in a Danish context (e.g. Carlsberg, Maersk, Novozymes, Danske Bank) or Danish branches of a global corporation (Deloitte Denmark) with the few smaller ones still top players in their field (e.g. COBE and IC Group). We targeted respondents 'purposively' (Guest et al., 2006) to find managers with insight in, and impact on, their companies' strategy processes and who would be well versed in balancing short-term strategy with long-term aims and investment decisions at a corporate level. We gained access during 2014 and 2015 through networking and recommendations, and contacted the managers by email containing a thorough description of the research intent and dissemination goals. By targeting managers at the Executive Management level gender, age and ethnicity automatically became a dependent variable. In our preparatory work of reading websites, annual reports and published strategic aims, it became clear that 
executive boards in large Danish companies generally comprise white Danish males who are on average in their mid-forties. The few women who are on executive boards often occupy positions in HR and communication. Our all-male sample reflects this societal homogeneity.

The interview form was chosen as an efficient as well as compelling way to engage managers in dialogue about issues of strategy and the future beyond "the neutral exchange of asking questions and getting answers" (Fontana and Frey 2005: 696). Given that the topic of the far future is not traditionally engaged with in management discourse, there was a certain performativity in our semi-structured, "active" (Holstein and Gubrium, 2004) interview format which gently pushed managers out of their comfort zone and made them hesitate at times. Their phenomenological reflections could not have been traced in other ways that 'the corporation' can speak, such as in annual reports or in its marketing materials. These reports and materials would give us already-embedded constructions of the future based on, for example, existing governance structures.

We imagined top managers to be struggling with overwhelming short-term expectations, and were curious to understand (Fontana and Frey, 2005) how they engaged with the future. Fontana and Frey represent a multifaceted and interactive approach to interviewing, in which interviews are "interactional encounters" (2005:699) driven by 
deep curiosity, rather than "neutral exchanges" (2005:696). Would our managers have other temporal horizons than the usual financial quarter and year, and the typical 3-year 'strategic' outlook? What would they show us through their temporal lenses? What would be their core concerns and desires pertaining to distant temporal frames? We performed two pilot interviews that confirmed the relevance and intelligibility of our pursuit and allowed us to adjust questions and interview pace. We then conducted ten interviews in companies selected across a variety of fields. As previous research has shown, "small samples" can provide high explanatory power when participants "embody and represent meaningful experience-structure links" (Crouch and McKenzie, 2006:493).

We have anonymized all respondents and have given them numbers (R1-R10) that do not correlate to the order of appearance of the companies in the respondent overview table below. However, we will occasionally provide specific company vignettes as disguising the companies would make the examples too bland. In these cases again we ensured that cross-referencing of interviewees was not possible.

Insert Table 1: Respondent overview table about here

All interviews were semi-structured and lasted approximately 45 minutes. The majority 
of questions related to the temporality of existing strategic practices (e.g. "which different time horizons does your organization work with"), and interviewees were asked to elaborate on a situation or strategy in the company in which issues set in the future had been addressed. Each question allowed for further probing into interesting remarks or emerging themes. The last fifteen minutes we switched to the far future. Drawing on arguments for the power of surprise in ethnographic research (Louis, 1980) we asked the question: “Does your organization exist in 200 years?". The managers' surprise at this radical shift of temporal horizon helped us evoke rich reflections about the longevity of the organization and its role in society. Our reason for the 200-year horizon was threefold: we wanted to make sure that the perspective could not be captured by existing strategic means or visions; we wanted to go beyond the horizon of immediate generations (i.e. grandchildren); and we wanted to create a sense of 'archaeologies of the future' (Jameson, 2005) in which disruptive scenarios of a grand societal scale could be imagined and engaged with from the present.

Insert Table 2: Basic Interview Protocol about here

In small sample qualitative research interview protocols may fruitfully be analysed by "thematic strands extracted from the material by dint of the researchers' interpretive and conceptual efforts" (Crouch and McKenzie, 2006: 488). This allows for a different 
engagement with the material than, for example, large-scale, grounded theory approaches (Corbin and Strauss, 2008; Suddaby, 2006) in which data saturation is built up across several rounds of data collection, including a high number of interviews and extensive coding that leads to hierarchical data structures (Langley and Abdallah, 2011). Research has shown that saturation or thematic exhaustion may occur after as little as six interviews, provided a relatively homogeneous population and similar questions for all respondents (Guest et al., 2006). Our analysis worked from this premise, building codes from both the interview protocol (e.g. "temporal horizons") and a careful reading of the transcripts (e.g. "trimming operations"). We then further identified quotes and meanings from the interviews through the use of different codes. Concurrently to code development we constructed a mindmap to capture the underlying 'grids of intelligibility' of our managers, resulting in topics such as "Empty Futures”, “Temporal Compression", and "Back to the Core". Probing into and across codes, topics and theory, we developed the categories that our analysis builds on - such as those relating to financial growth and survival - and larger themes that structure our analysis - such as the agentic paradoxes that make conceptual repertoires start to stutter.

In the next section we will first present the common-sense frame with which our interviewees engage the future. The vast bulk of our interview material, well in excess of $90 \%$, was taken up with conceptual webs and calculative devices that aim to bring the future into the present and which are in turn entangled in the material realities (e.g. 
responsibilities towards clients and shareholders) our respondents faced on a daily basis. In the first sub-section we aim to map the work these managers do with particular concepts as well as the work these concepts explicitly or inadvertently exert on them. As outlined above, we are particularly interested in the instances where what is generally affirmed as clear, reasonable and common sense does not quite hold anymore, which is sometimes subtly expressed as something "amiss" or "not quite covered" by our interviewees. We sifted our interviews for these instances when reservations were expressed and we reflected analytically on some of the paradoxes particular framings throw up, as well as on what such framings disregard: agency and ecology in particular. In a third and final sub-section we introduce a certain displacement of our angle of vision and explore some examples of different 'attunements' that adumbrate a possible different engagement with the future.

\section{Framing of the future in the case companies}

\section{Bringing the future into the present, or extending business-as-usual}

At first glance, the argument that we live in a "contemporary imprisonment in the present" (Jameson, 2015: 120) seems contradicted by the unfolding of so much corporate energy directed towards the future. Growth ambitions, strategic goals, R\&D the crux of attention in corporate life seems on change rather than permanence, future 
rather than present. These changes, however, are structured to take place within a generic temporal order, described across all our interviews in three quite similar futures horizons: One year; three to five years; and 'long term' (10-15 years), the latter described as "marathons" (R.3) and "considering the next generation" (R.5). From a company perspective, much of managerial time and effort is spent on navigation towards the short and medium-term future within the parameters set by 'the market'. The institutional embeddedness in capitalist financial structures very much sets a certain agentic baseline:

"We are very short-sighted - even though we say that we are projecting the next three years. But it is very short-sighted. We have to deliver every quarter. That's how it is when you're a listed company" (R.3)

These short-term quarterly performances feed into the medium-term perspective in which companies must sustain growth. Across our case companies, managers invariably referred to growth goals as core to their future related strategy work; for example " $10 \%$ of turnover" (R.3), "to be undisputable market leader" (R.2) or "15\% growth in economic profit every year..." (R.4). This construction of growth as the goal in organizational life does not command any explanation other than itself. As the manager justifying the $15 \%$ growth target reasoned: “...because it's damn good performance” and "there's money in it, for management and shareholders" (R.4). Shareholders are the 
focus when managers explain strategic choices: "We are obligated towards our owners. And we must offer decent returns to our owners" (R.5).

The mid-term temporal horizons build on the well-known linear understandings of time that underpin the capitalist mode of production. This is not just an un-reflective modus operandi for managers, but a serious commitment to action:

"If you go out any further [in time], you can't really...it just gets too vague and non-binding. Commitment starts when you talk about a level of performance and results that must be performed within the next 36 months; which you can begin to transform to operational plans for the next 12 months, which must logically lead to where you need to be in 36 months. If you begin to talk to me about a place you want to be in five years... [sighs]" (R.4).

Although the short- and mid-term activities are characterized by rather strong agency; these choices concurrently help to create the strangely "neutralized future" that Jameson (2005: 228) propounds, which is less about future visions than about surviving in 'the market'. Companies must play by the market rules to reach the future, perspicuously expressed by several managers as a "need to win": a "primary task to win and earn a lot of money every quarter" (R.3); a decision to "only be in those business areas where we say that we can really make a difference - where we can win in the market and be what 
we call top quartile" (R.9); a constant question of "can we beat [our competitors]?" (R.10). This future is not a place for collective opportunity and imagination, but more a zero-sum game marked by an individual evolutionary struggle for survival. If you do not stay on top of the game, keep winning, then you will be bought-out or die. The outcome of investing too readily in the long term future is indeed described as "dying" by some (R.10), which is not an unusual turn of phrase in business lingo. This discourse of dying is revealing though: you must not run too far ahead or you die; you must play by the rules, or the rules cannot support you and you die. All this is interpreted as if it is an iron law, expressed by one manager as, "we will go where the business opportunities are" (R.9); framing business opportunities and the company's need to pursue them as a near-Darwinian phenomenon.

Mapping contradictions and conditions of disregard, or where conceptual repertoires start to stutter

The markets in which companies find themselves are subject to a mode of "exponential acceleration" (R.6). Managers expressed the need to experiment, to use their "gut feeling" (R.8) and try to "fail fast - fail forward" (R.7). They exercise agency by making "big bets" (R.2), by "having several bets out there [at the same time]" (R.5), by getting "wild ideas" in collaboration with universities or "garage innovators" (R.7), and they "spend lots of resources testing" before deciding to scale up anything (R.3). The 
pace (or temporality) of change in the markets is accompanied by an equally accelerating scale (or spatiality) of change. Trends and emerging new products and practices are interconnected, global and do not stay neatly within defined markets. There is no certain way of knowing these changes, so managers simply stay alert and ready to change; "you make a plan [...] and then things just come at you from right and left, and you have to adjust" (R.7), "calibrating" (R.5) between the expected future and present agency and scanning the horizons with their chosen strategic tools.

The other dimension of this flexibility in the face of constant uncertainty is a rational linearity that correlates future ambitions and assessments with present resources. Much future-oriented activity is bound up with such "resource commitments" (R.6) where experimentation is reined in through the trimming of existing processes and activities. To be flexible and hit emerging trends right, companies need to get rid of surplus fat so they can move quickly and efficiently. Many companies have centralized and trimmed capital allocations and/or strategic structures, so that activities are financed strictly to match business targets, making operations leaner and more profitable (R.4, R.5, R.7, R.9, R.10). When the future demands extreme flexibility and adaptability, companies cannot have resources bound up in all sorts of organically grown activity; they must be focused and ready to select and invest 'responsibly' in the future. In the words of one manager: 
"We are a big and complex organization, [and] we have to have systematic capital allocation. [...] We have to have a systematic, coherent strategy that we can explain to our shareholders [and others] and say 'this is what we want to do with your money, this is what we will focus on'. [We] have become much more disciplined around capital allocation [and] strategy execution, and have created a good platform" (R.9).

Coherent strategic platforms, transparent frames for regional and central responsibilities and trimmed product portfolios have become increasingly core to managers' work. With these in place innovation is expected to unfold more efficiently, whilst supposedly generating the independent thinking that change demands: a paradoxical 'structured deviance' as it were. This positions our case companies in a bit of a temporal fix: the present is constantly rationalized and submitted to non-negotiable saving targets, so that companies can instead spend resources on the future. But the future in this particular framing only has relevance insofar it is profitable - which by default limits experimentation and innovation to calculable contents and time spans. The indeterminacy of accelerating change thus creates an uncanny sense that agency and reality do quite not match up (Morton, 2013). The current tools and concepts to engage the future seem to be made for a lost and "sturdier" past in which the future could be planned (R.6). The further into the future companies project, the less precision they get 
in terms of fitting resources to future results. There is thus an in-built dislocation of the 'unknown' future in the economic calculations of rational modern strategy: numbers demand certainty, time decreases it. Managers need to make some sort of calculations when assessing future investments, even when these are difficult to perform. One manager expressed the temporal limits of such calculations succinctly:

"We prefer to do it [the calculations] on 5-year horizons, we also do it on 10 years, and we also have some [investments] where we do it on 15 years. But if you get out..., I mean, of course if you have a WACC (Weighted Average Cost of Capital) of [...] 5 per cent, then a 10-year horizon is...then there's not much left when you get out there." (R.6)

And whilst our interviewees speak for their organizations and express the logic by which they operate, they are also well aware that the complex and unpredictable world of future markets is far removed from the predictions needed for their investment, thus causing quite a few paradoxes in corporate strategic practices. As one manager suggested rather wryly:

"We can be absolutely sure that our assessments of the price of [this] in 2035, and of supply and demand, will turn out to be spectacularly wrong, but at least we have a structured approach to it based on analyses and studies." (R.9) 
When we asked managers how they imagined their organization in a temporal frame beyond their own farthest temporal horizons, interesting perceptions of time and history surfaced. Organizational navigation in this very long term seems quite arbitrary to managers, if not futile.

"If I look at how technology has developed over the last 10 years and multiply that with 20 and then include an exponential factor on top of it, well it just wouldn't make any sense to talk about our technology and organization in a 200year perspective." (R.6)

For our interviewees 'duration' is a question of what we would call 'chronologically matching' past patterns of corporate survival with future likelihood of the same patterns. For example, companies with a long history more easily imagine their existence in 200 years than younger companies, and longevity has greater value to them as a mode of permanence and proud traditions. The majority of managers, however, do not imagine that their companies will exist in 200 years' time and they use chronological history to justify this in statements such as "just take the Fortune 500 list and look at it over the last 60 years and see how many are left" (R.4), or "if you look back just 50 years and look at Top 100 of companies in the world, there's maybe $10 \%$ of them left" (R.9). 
Our interviewees live by an almost paralyzing historical knowledge that technology constantly changes and disrupts organizations and does so at increasing speed. One's own organization in that perspective becomes insignificant; a contingent effect of technological progress. The role of the corporation in contributing to a collective future thus seems neutralized, as expressed by one manager:

"I think that the company is a construction, right; a way to organize people and capital to solve problems. And get paid for it in the process. That is the problem we solve $[\ldots]$ we will hopefully get so good at what we do, that we can solve a broader range of [company specific issues] in that basket. It's not on the cards that we will start solving some other problem entirely." (R.4)

This company-as-construction does not have a historical or societal imperative; it mainly relates to the change that happens around it, and it seeks to be relevant in that realm. To consider larger societal issues or remote future horizons in business strategy is seen as simply rather naïve.

And even if they should want to engage more fully with the future, this is challenging because core products and services are based on serving present needs. For our manager at Rockwool, for example, it is possible to conceive of ways of living which will "leave no footprint" and where advanced insulation technology can play an important role. But 
to move from a present position in the market to long-term collective needs throws up a paradox:

"Oh dear, oh dear... That would be to look at what we deliver beyond insulation. I mean, if we still see ourselves as a company that just delivers insulation to customers based on their specs, we are not part of redefining the market.... [To take] part in describing the housing of the future, [we need to address] building regulation. [...] But then keep in mind that the people we interact with, they are entrepreneurs, so if you talk 2020, they are gone. If you talk 200 years, they are way gone, right (laughs). [...] We become part of the people we talk with, and that reflects deeply on us, so then we get back to this thing that when I start bringing these topics to the table; well you can almost hear the kind of feedback I get: "Well that's just dandy, but that's not what our clients are asking for". So we do have this paradox of being kept very much in the present."

\section{Opening up the present to the future (and the past)}

What, then, can connect present action with different dimensions of time? In this final part of the analysis, we will trace examples of managerial reflections and practices transcending or exposing the prevailing frames to corporate temporal agency. For architectural firm COBE, building for the future is ingrained in their basic work 
practices, as perhaps can be said of city planning architecture in general. However, at COBE products are weighted with inter-temporal responsibility:

"When you put bricks on top of [each other], you need to do it in a clever way. It should be able to last for 200 years. Because it is no good if it only lasts for 30 or 40 , and then you have to rebuild."

This technical fact of building resilient structures is then complemented by a social fact; that both collective and individual needs will change drastically over the decades. This fact, as we have described earlier, makes for a corporate view that it is impossible to know today what to aim for in product development in the long run, making strategic engagement with collective needs in the far future effectively impossible. COBE works with this impossibility by not trying to imagine what that future will be like, but instead by designing space for the architects and inhabitants of the future to integrate their own needs and visions. In an urban planning project in Copenhagen where over the next 4050 years an entirely new neighbourhood (Nordhavn) will emerge, COBE has therefore actively left room for future generations' work. They do this by, for example, only filling out part of the area plan and leaving spaces open for future architects and citizens. The CEO and founder explains this approach with a simple analogy: 
“It's like a Christmas calendar with 24 numbers, where we have loosely placed each wicket, [and] then the idea is that you start by opening wicket number one and then number two [...], but what's inside wicket $6,8,10$ or 24 ; well they might only be opened in 10-15 years. Other architects may have to design what's inside them."

Allowing for space-to-come, and tangibly strategizing to create relevance for that space, seems to add a virtual dimension to existing work in the present and thus connects it to a distant future without getting trapped in linear predictions or an overwhelming sense of historical progress, speed and acceleration.

An alternative to making space for the future is to excavate the present, redeeming existing but ignored knowledge. In Coloplast, the core business of stoma care went through a strategic turnaround based on rich, experience-based 'human' data rather than traditional financial data from different segments, units and geographies in the company.

"The data you need to create commercial redemption for something is completely different. [...] You take a business area and decide that 'this we want to understand, and we will rediscover it'. Then you need richer data; with texture. And you must enter decision processes more related to aesthetics and judgment than to equations. [...] To understand stoma care, you must understand what 
happens with these people. What is it they experience? [...]You look at diaries. You look at video recordings. You look at situation-based interpretations from anthropologists and ethnographers. And this is a very different discipline than the first one [financial data]. [...] I have named it commercial redemption, right [...]. When you drill far down in your business, you can rediscover things and see opportunities. And when [that] knowledge is internalized in the minds of central decision makers, and they gain comprehension, then they can make better decisions. They can see more opportunities and make better decisions. The problem is that a large number of people have no interest in that stuff."

Impulses toward the future here come from past and present experience, anchored in people's phenomenological engagements with the world, rather than from projections. At issue is the possibility of activating certain ignored elements and sensibilities in new and unexpected ways. This suggests a break with the calculation of the value of activities for future earnings: a temporary space is created where the realities and lives that products touch are explored. You "see opportunities" in the neglected and overlooked patterns of your business by not moving forward. These are then of course re-appropriated into business strategies, product development and calculations of future earnings potential. But it shifts the premise of these future earnings from something 'liquid', always in progress, to something solid: what human beings do, think, and struggle with on a daily basis. 
Across the majority of our interviews, heritage appears as another temporality that brings both past and future to life. It invokes permanence and generational responsibility. In the words of one manager: "there is something alluring in creating something with the robustness and strength to last for generations" (R.8). One of our managers thinks back to his time as CEO of historic Danish porcelain company Royal Copenhagen and reflected on the "pride of working for a 240 year old company":

“There's a reverence to working for a company of that age. And there's also a different kind of responsibility to it, you know. I am passing on the baton, there may be 50 or 60 CEO's before me, you know, and there I've been given the baton to run with and pass. I am just a provisional figure."

Being part of something solid and permanent has an almost sensuous quality to it, a deep engagement with collective history separate from competitive pressures. Permanence also has very tangible effects on companies' abilities to manoeuvre and grow. Several managers expressed their specific 'foundation majority-owners' construction $^{5}$ as the way of building for the longer term:

\footnotetext{
${ }^{5}$ In Denmark the shareholding majority in several large companies is kept with either the founders or a legally separate foundation often created by the founders, thus shielding the company from (hostile) takeovers. These foundations support societal and cultural interests. For example, the A.P. Møller (Mærsk) foundation donated a new opera house to the city of Copenhagen and supports NGO's, hospitals and more. The Carlsberg foundation supports science through postdoctoral grants and large crossdisciplinary project funding.
} 
"I think that [having the ability to survive in the long run] is something as banal as having an extremely long-sighted owner. So the company is not for sale. If else, then... well. [It would be gone.]" (R.4).

"I can say that if [the company] were not foundation owned, then this organization would not exist. Because then we would simply have been too small. We would have been bought up. And split up, and called something else, that sort of thing." (R.3).

This foundation model in the long term also transforms economic profit into social value, connecting short-term business interests to the development of society:

"So if something exists [in 200 years], it will be our culture and values that we want to contribute with, and we want to contribute to society. Because we are privately owned, [our ownership foundation] takes care of a lot of the societal needs $[\ldots]$ and you can say that if they give [money] to education, or to... It is the foundation that does it, that owns the shares, but the money for it [the foundation's social investments] is generated from here [the business]. So you could say; who really carries that responsibility?" (R.9)

It appears that the long-term view is somewhat beyond the market. To play and win in the market, organizations must paradoxically place themselves partly outside it. And, as 
the quote above suggests, although companies first and foremost must create profitable growth for shareholders; if they are foundation-owned the line between economic and social purpose ultimately becomes blurred. In this sense, the market becomes a means for non-market practices.

When asking managers more directly about important societal problems that need to be solved over the next 200 years, in which their company would or should play a role, their immediate reactions were to externalize and sometimes even trivialize the problems. In 200 years' time, issues of climate change, for example, are expected to be "solved long ago" (R.3); the world will have a "completely different approach to energy" (R.7) and even though we "haven't cracked the nut on global warming [...], we have survived all sorts of things and found solutions, [...] so at some point in time we will find a solution to [that and] most problems" (R.10). However, in relating present action to these otherwise externalized problems, some managers did make some connections as, for example, in the case of Novozymes:

"We play into it in the sense that what we do today has impact on how the world looks in 100 or 200 years, at that the directions we [as a company] try to develop and implement now will create the foundation for those who come after us, right. So if we pull in one direction saying 'let's burn some more oil', well that's one future that our grandchildren can take over. If we say that we need to take a 
different direction and produce in a way that stops the release of $\mathrm{CO} 2$ and stops the release of non-biodegradable chemicals in the soil and the atmosphere, well then that's another future for our grandchildren to build on".

\section{Discussion: the commitment to efficiency and alternative temporal attunements}

It is not difficult to discern the broad outlines of an ideological framing in the tales of our respondents. In such a frame the future becomes bound to the structures of growth, technology and performance so fundamental to capitalist organizing. The more distant future is not tied to any tangible translation from the present onward, but is rather at the mercy of technological developments which are treated as if they, "were a kind of black box, capable of solving all problems of organization in a quasi-magical way, so that they do not any longer have to be addressed and concretely imagined or organized into thought experiments" (Jameson, 2016: 46). Jameson refers to this ensemble of notions around technology and progress as "the ideology of efficiency" and he believes that the commonsensical commitment to 'efficiency' as fundamental value “motivates our wellnigh libidinal commitment to capitalism itself as a system" (Jameson, 2016: 49-50).

We observed this commitment to efficiency as a particular manifestation of the capitalist ideology of time that guides our managers' engagement with the future. Though they anticipate big changes and in some instances relate themselves to these (as 
our Nozozymes manager with climate change), their dominant reflections show a disassociation of their own present actions from these changes. While our respondents are incredibly agentic, handling the pressures and changes of accelerating and interconnected markets, calculating the future into earnings potentials, and setting a series of milestones in the present to reach these potentials; they exercise their agency within a particular grid of intelligibility. They operate within a logic of survival and winning in the game of the market, and their efficiency measures of trimming capital allocations, creating lean processes and calibrating strategies to technological developments all serve this end.

When embracing futures beyond the general strategy horizons, the pervasive efficiency framing dissipates and corporate agency tends to be conceived in a discourse of fluidity. The changes in business and society happen at a pace that leaves individual actors and organizations seemingly powerless. In imagining their own companies' future existence managers 'chronologically match' the company survival statistics of the last 60 years with the likelihood of their own company's survival. Extrapolating the future from the past is not an odd thing to, but what is interesting is that this imagination stays stuck at the aggregated level of business lingo (e.g. the Fortune 500) and does not relate to how these companies mattered to their world; how they shaped and were shaped by the environments in which they operated. The future in this business perspective seems about the pace of technological change. Not as the yet to be imagined visions that will 
enable changes, not the resources, structures and beings that will support these changes; just as sheer awe in the face of acceleration. In this experience of the world, there really is no temporal orientation: all is flux. One could argue that the ability to embrace flux actually points to a different and much more sophisticated agency than critical scholars would usually credit managers with, but this embrace involves little phenomenological engagement; flux appears as an externalization of the goings-on of the world.

The practices and beliefs of efficiency and flux make up the larger part of everyday corporate strategy. Pursuing our interest in 'sorting out those parts of the present that might lead to the future' (Tsing, 2015:20) we also caught glimpses of a different kind of managerial agency and utopian thought that connects our actors to people instead of 'markets', and to collective problems instead of abstract acceleration. In relating to disruptive futures by changing current production patterns, in redeeming human agency from the deep present, and in honouring the beauty of heritage, managers express a certain cross-temporal 'intimacy’ (Morton, 2013). Our Novozymes manager works to "produce in a way that stops the release of CO2" and our Rockwool R\&D director imagines how to create sustainable "housing of the future" (before putting a stop to it with it with the reflection: "but that's not what our clients are asking for"). Coloplast tries to achieve "commercial redemption" for its products, and COBE collaborates with actors not yet known to them, making room for the future to arrive on its own terms. These are only isolated incidents, bits and pieces that are somehow askew and out of 
place, but they are nonetheless significant. They are temporal attunements with the potential to bring out the "expansion of desires, of needs, of lifestyles, of communities, of ways of being, of capacities" that Srnicek and Williams (2015:181) call for.

Furthermore, in reflecting on our questions about the very long term perspective for their organizations, our respondents revealed that temporal structures such as heritage, stability and independence from market frenzy were core to their existence, creativity and, in some cases, even pride. The societal contributions by the large foundations bring a different temporality into the picture; the desire to engage with long-term issues such as education, healthcare or art which are temporally and spatially distributed. And the family or foundation based structure of ownership in some of our largest case companies shields them from short-sighted financial practices and makes it possible to span across generations and develop an intertemporal commitment to the quality of their products. Certainly, it could be argued that non-market constructs like foundations are exactly the auxiliaries that market mechanisms rely on to keep otherwise dysfunctional structures in operation. The 'foundation' model can easily be criticized for showing a more humane and long-term face of capitalist organizing, while contributing little in terms of the 'utopian surplus' needed to create a truly new and different future. Nevertheless, the foundation model shows us some of the cracks and variations in market practices and thus offers us a more nuanced perspective on the role of 
companies in late capitalism (Morton 2013:154f.). The market is not all what it seems, and not all of its actors follow only its dominant rhythms.

Business-as-usual is marked by short term orientations that are continuously constituted in the material practices and rational demands of everyday corporate strategy making, thus demonstrating at a meso-level the dysfunctionalities of contemporary capitalism in solving social and environmental problems of the present and future. As Morton (2013: 21) put it, because "the raw machinery of capitalism is reactive rather than proactive", it contains "a flaw that makes it unable to address the ecological emergency fully". Largescale social and environmental concerns, such as climate change and 'planetary boundaries' (Rockström et al., 2009), lie beyond capitalism's reactive mode of operating. There is little to be found of the "appropriate level of shock and anxiety" required to deal with the unfolding "ecological trauma" (Morton, 2013: 8) among our interviewees. But even beyond that, they seem to hold on to a belief in capitalism as a social order held together by a promise of boundless progress. Yet, recent developments - we only have to think of Brexit, the Trump presidency, the faster-than-projected melting of Arctic and Antarctic ice - have very much put into question capitalism's "air of careless munificence" (Kunkel, 2014:16).

The rationality of our managers as spokespersons for their organizations seems to be based on a strange absence of agency concerning collective problems that are beyond 
the capacity of the market. This is not to say that their products and services do not create societal value - obviously stoma pouches, bio-ethanol, insulation, buildings, shipping and so forth are of deep value to the functioning and development of modern societies. But there is a mismatch between the global problems that managers see and the corporate engagement they deem possible. The distant future is just not conceivable in its magnitude so they deal only with the manageable side of it, which they project onward from the present through ideals and devices of efficiency. An "asymmetry between action and reflection" (Morton, 2013: 160) seems at play, expressing itself either in a belief that technology will magically put things right, or in a paralysis bordering on the painful experience of depression (Fuchs, 2001; Rosa, 2013).

The obvious limitations of companies to understand and engage with long-term societal and systemic problems makes it seem productive to search for a "utopian edge" (Srnicek and Williams 2015:108) outside the capitalist 'machine'. Much as such an ideal appeals to us, we wonder if traces of this edge can also be found in the individual and organizational experiences 'inside the machine'. Thus, we have endeavoured to explore agency that takes place in the cracks of corporate life. The "stirrings of a different state of things" (Jameson, 2009: 416) are immanent in the present and this present is populated by all sorts of actors (Morton 2013). Limited as our corporate actors may be in imagining social change, they possess a treasure trove of experiences about carving out temporal agency, about relating to futures outside the market even 
when inside, and about sensing a connection to both future and past whilst being frustrated about not being able to address these due to frantic market demands. It is in the details of these experiences, and not least their frustrations, that we have looked for traces of utopian thought.

Morton proposes the 'hyperobject' as a concept for engaging utopian sensitivity and a way of situating our current experiences in vast temporal and spatial relations. The engagement with such objects requires "a vision of interlocking, yet somehow also alternate, worlds, in which beings of brief life spans are also the components of enormous and properly unimaginable totalities which develop according to vast and inhuman rhythms, and in a different temporality altogether" (Jameson, 1988: xxviii). This engagement is not rational and cannot simply be handled with organizational tools and strategies. Rather, hyperobjects are revealed to us in 'sensual qualities' of their current and local manifestations that we can feel, taste, think and relate to. They thereby also evoke a certain weakness in our agentic beings and expose the hypocrisy of our ‘deeply flawed' utilitarianism (Morton, 2013:135ff.). Some of our respondents expressed this uncomfortable feeling when troubled about the effects of climate change on future generations (as in the Novozymes example) or in the uncategorisable moment when our fashion CEO suddenly and unexpectedly elucidated the "conditions of disregard' (Stoler, 2016) in his business: 
"With a brand like [this outdoor brand], where we just love to ski, and we love to be in nature, $[\ldots]$ will we have glaciers, and will we have snow, in the future? And the more we push, that is the more we promote skiing, the more we burden those areas. [...] There's something difficult in being sustainable and in balance with nature and then saying 'go ahead and come in the thousands to ski those mountains, and let's get some gasoline fumes up there over the tree line, right! I mean, it's really, really difficult to win that one."

Faced with such looming disruption, corporate temporalities arrive at an impasse. Our respondent squarely faces the weakness and hypocrisy of the fashion industry towards problems of pollution and climate change, being well aware that there is no fix. We observed such honest reflection and concern across several of our respondents, when they hinted that their strategic practices needed to reflect entirely different temporalities to create more than financial value. Following Morton, it is exactly in these concerns that the attunement to a different future begins: in the weakness, lameness and hypocrisy of our human agency towards the enormous human-nonhuman objects in which we are entangled. 


\section{Conclusion}

Our study has concerned itself with the ideology of time in corporate agency: by initially paying attention to the ways managers are drawing the future into the present, and then focusing on the things that escape their tried and trusted conceptual repertoires, however small and marginal they may be. Exposing this ideological dimension of temporality shows capitalism's in-built failure in terms of solving large-scale, long-term problems. Noticing what falls outside, we find traces and clues of managers working against the grain of the temporal ideology that dominates their worlds. A question for further research would be to understand better how these traces arise and work under the radar of capitalist time, and to explore whether corporate actors' experiences with alternatives reveal new agentic inroads to opening up capitalist organizations to the collective, the entangled, the pressing - to a future that is qualitatively different from the present.

Doing so would pay heed to Jameson's (2009: 579) assertion that the "recognition but also discovery, the identification of agents not yet fully visible, the reorganization and redistribution of the actantial field" is an indispensable preliminary moment for restoring historicity to our present. Understanding such a reorganization of actantial fields as a practice that describes organizational environments in the present and their imaginative possibilities to become otherwise, is part of how we might set in 
motion possible futures that are not simply a prolongation of the present (Yusoff, 2010). This is where we hope the positive contribution of our paper lies: that we should see the future always-already breaking into the present, and convincing our readers that the "stuff" that does not fit so easily within the capitalist growth machine does matter. It matters a lot if we want to keep the future vibrant, real and alive. 


\section{References}

Bansal, P., \& DesJardine, M. R. (2014). Business sustainability: It is about time. Strategic Organization, 12(1), 70-78.

Bauman, Z. (2000). Liquid modernity. Cambridge: Polity.

Benjamin, W. (1999). Illuminations (H. Zorn, Trans. H. Arendt Ed.). London: Pimlico.

Benjamin, W. (1940). On the concept of history. In H. Eiland, \& M. W. Jennings (Eds.), Selected writings, volume 4: 1938-1940 (). Cambridge: Harvard University Press.

Bennett, J. (2010). Vibrant Matter. A political ecology of things. Duke University Press.

Boltanski, L. (2011). On Critique: A Sociology of Emancipation. Cambridge: Polity.

Corbin, J., \& Strauss, A. (2008). Basics of qualitative research. Thousand Oaks, CA: Sage.

Crane, A., Palazzo, G., Spence, L. J., \& Matten, D. (2014). Contesting the value of 'creating shared value'. California Management Review, 56(2), 130-153.

Crouch, M., \& McKenzie, H. (2006). The logic of small samples in interview-based qualitative research. Social Science Information, 45(4), 483-499.

Eiland, H. \& Jennings, M. W. (2014). Walter Benjamin: A Critical Life. Cambridge (MA): Belknap Press.

Fisher, M. (2009). Capitalist Realism: Is There No Alternative? Winchester: Zero Books.

Fontana, A., and Frey, J. H. (2005). The Interview. From neutral stance to political involvement. The Sage Handbook of Qualitative research, 27, 695-727. Thousand Oaks, California: Sage.

Frase, P. (2016). Four Futures: Visions of the World After Capitalism London: Verso.

Fuchs, T. (2001). Melancholia as a desynchronization: towards a psychopathology of interpersonal time. Psychopathology 34 (4),179-186.

Gayá, P., \& Phillips, M. (2016). Imagining a sustainable future: Eschatology, Bateson's ecology of mind and arts-based practice. Organization, 23(6), 803-824.

Ghosh, A. (2016). The Great Derangement: Climate Change and the Unthinkable. Chicago: University of Chicago Press.

Gosling, J., \& Case, P. (2013). Social dreaming and ecocentric ethics: sources of non-rational insight in the face of climate change catastrophe. Organization, 20(5), 705-721. 
Guest, G., Bunce, A., \& Johnson, L. (2006). How many interviews are enough?: An experiment with data saturation and variability. Field Methods, 18(1), 59-82.

Haraway, D. J. (2016). Staying with the trouble: Making kin in the Chthulucene. Duke University Press.

Ho, K. (2009). Liquidated: an ethnography of Wall Street. Duke University Press.

Holstein, J. A., \& Gubrium, J. F. (2004). The active interview. Qualitative research: Theory, method and practice, 2, 140-161.

Jameson, F. (1988). The Ideologies of Theory: Essays 1971-1986 (Vol. 1). London:

Routledge.

Jameson, F. (1989). The Ideologies of Theory: Essays 1971-1986 (Vol. 2). Minneapolis: University of Minnesota Press.

Jameson, F. (2003). Future City. New Left Review, 21(3), 65-79.

Jameson, F. (2005). Archaeologies of the future: The desire called utopia and other science fictions. London: Verso.

Jameson, F. (2009). Valences of the Dialectic. London: Verso.

Jameson, F. (2015). The Aesthetics of Singularity. New Left Review, 92: 101-132.

Jameson, F. (2016). An American Utopia. In S. Žižek (Ed.), An American Utopia: Dual Power and the Universal Army (pp. 1-96). London: Verso.

Jameson, F. (2016b). An American Utopia: Epilogue. In S. Žižek (Ed.), An American Utopia: Power and the Universal Army (pp. 309-317). London: Verso.

Joas, H. (1996). The creativity of action. Chicago, IL: University of Chicago Press.

Klein, N. (2014). Climate change is the fight of our lives - yet we can hardly bear to look at it, Guardian. Retrieved from http://www.theguardian.com/commentisfree/2014/apr/23/climatechange-fight-of-our-lives-naomi-klein

Koselleck, R. (2004). Futures past : On the semantics of historical time. New York, NY, USA: Columbia University Press.

Kunkel, B. (2014). Utopia or Bust: A Guide to the Present Crisis. London: Verso.

Langley, A., \& Abdallah, C. (2011). Templates and turns in qualitative studies of strategy and management. Research Methodology in Strategy and Management, 6, 201-235. 
Louis, M. R. (1980). Surprise and sense making: What newcomers experience in entering unfamiliar organizational settings. Administrative Science Quarterly, 25(2), 226-251.

Moore, J. W. (2015). Capitalism in the Web of Life: Ecology and the Accumulation of Capital. London: Verso.

Morton, T. (2013). Hyperobjects: Philosophy and Ecology after the End of the World. Minneapolis: University of Minnesota Press.

Nyberg, D., \& Wright, C. (2016). Performative and political: Corporate constructions of climate change risk. Organization, 23(5), 617-638.

Painter-Morland, M., \& Ten Bos, R. (2016). Should Environmental Concern Pay Off? A Heideggerian Perspective. Organization Studies, 37(4), 547-564.

Powers, R. (2005). An Artificial Being. In B. Latour \& P. Weibel (Eds.), Making Things Public: Atmospheres of Democracy (pp. 614-619). Cambridge (MA): MIT Press.

Rosa, H. (2013). Social acceleration: A new theory of modernity Columbia University Press.

Savage, M., \& Williams, K. (2008). Remembering elites Wiley-Blackwell.

Srnicek, N., \& Williams, A. (2015). Inventing the Future: Postcapitalism and a World Without Work London: Verso.

Stoler, A. L. (2010). Along the Archival Grain: Epistemic Anxieties and Colonial Common Sense. Princeton/Oxford: Princeton University Press.

Stoler, A. L. (2016). Duress: Imperial Durabilities in Our Times. Durham: Duke University Press.

Streeck, W. (2016). How Will Capitalism End? Essays on a Failing System. London: Verso.

Suddaby, R. (2006). From the editors: What grounded theory is not. Academy of Management Journal, 49(4), 633-642.

Tsing, A. (2015). The Mushroom at the End of the World: On the Possibility of Life in Capitalist Ruins. Princeton (NJ): Princeton University Press.

Urry, J. (2008). Climate change, travel and complex futures. The British Journal of Sociology, 59(2), 261-279.

Wallerstein, I., Collins, R., Mann, M., Drerluguian, G., \& Calhoun, C. (2013). Does Capitalism Have a Future?. Oxford: Oxford University Press.

Wittneben, B. B. F., Okereke, C., Banerjee, S. B., \& Levy, D. L. (2012). Climate Change and the Emergence of New Organizational Landscapes. Organization Studies, 33(11), 1431-1450. 
Wolf, M. (2016). An end to facile optimism about the future, Financial Times. 12 June. Retrieved from http://www.ft.com/cms/s/0/5d10878a-4788-11e6-8d6872e9211e86ab.html\#axzz4EHTF0Vz5

Wright, C., Nyberg, D., De Cock, C., \& Whiteman, G. (2013). Future Imaginings: Organizing in Response to Climate Change. Organization, 20(5), 647-658.

Yusoff, K. (2010). Biopolitical Economies and the Political Aesthetics of Climate Change. Theory, Culture \& Society, 27(2-3), 73-99 
Table 1: Respondent overview table

\begin{tabular}{|c|c|c|c|c|c|c|c|c|}
\hline Name & Organization & Org. Type & Ownership & Title & \begin{tabular}{|l} 
Executive \\
Board \\
member
\end{tabular} & Gender & Ethnicity & Exec. Board composition in company \\
\hline \multirow{10}{*}{ ANONYMIZED } & Carlsberg & $\begin{array}{l}\text { Consumer } \\
\text { goods }\end{array}$ & $\begin{array}{l}\text { Industrial } \\
\text { Foundation }\end{array}$ & $\begin{array}{l}\text { Senior Vice President } \\
\text { Western Europe }\end{array}$ & Yes & Male & White & $\begin{array}{l}\text { Ten people, mixed white European, } 8 \\
\text { male } 2 \text { female (HR \& Corp.Affairs) }\end{array}$ \\
\hline & COBE & Architecture & $\begin{array}{l}\text { Limited } \\
\text { Liability comp., } \\
\text { founder owned }\end{array}$ & CEO \& Founder & Yes & Male & White & $\begin{array}{l}\text { No EB - "Managing team" of } 2 \text { male } \\
\text { (CEO + Managing Director) } 2 \text { female } \\
\text { (Dir. Bus.Dev. + Managing Director), } \\
\text { white Nordic }\end{array}$ \\
\hline & Coloplast & Healthcare & $\begin{array}{l}\text { Industrial } \\
\text { Foundation }\end{array}$ & $\begin{array}{l}\text { Senior Vice President } \\
\text { Chronic Care }\end{array}$ & Yes & Male & White & Four people, all Nordic white male \\
\hline & $\begin{array}{l}\text { Danske } \\
\text { Bank }\end{array}$ & Finance & Public & $\begin{array}{l}\text { Head of Business } \\
\text { Banking }\end{array}$ & Yes & Male & White & $\begin{array}{l}\text { Seven people, mixed white European, } \\
\text { all male }\end{array}$ \\
\hline & Deloitte & $\begin{array}{l}\text { Accounting \& } \\
\text { Consulting }\end{array}$ & Public & CEO & Yes & Male & White & $\begin{array}{l}\text { Two people in EB, Nordic white male, } \\
\text { otherwise partner-driven }\end{array}$ \\
\hline & $\begin{array}{l}\text { Haldor } \\
\text { Topsøe }\end{array}$ & Biotech & Family Owned & $\begin{array}{l}\text { Group Vice President } \\
\text { Engineering Production }\end{array}$ & Yes & Male & White & Ten people, all Nordic white male \\
\hline & IC Group & Fashion & Public & CEO & Yes & Male & White & - \\
\hline & Mærsk & Oil \& shipping & $\begin{array}{l}\text { Industrial } \\
\text { Foundation }\end{array}$ & $\begin{array}{l}\text { Vice President Risk } \\
\text { Management, CEO } \\
\text { Insurance }\end{array}$ & No & Male & White & Six people, all Nordic white male \\
\hline & Novozymes & Biotech & $\begin{array}{l}\text { Industrial } \\
\text { Foundation }\end{array}$ & $\begin{array}{l}\text { Executive Vice President } \\
\text { Business Development }\end{array}$ & Yes & Male & White & $\begin{array}{l}\text { Five people, } 4 \text { Nordic } 1 \text { UK, all white } \\
\text { male }\end{array}$ \\
\hline & Rockwool & $\begin{array}{l}\text { Construction/ } \\
\text { engineering }\end{array}$ & $\begin{array}{l}\text { Industrial } \\
\text { Foundation }\end{array}$ & Vice President & No & Male & White & $\begin{array}{l}\text { Five people, mixed white European, } 4 \\
\text { male, } 1 \text { female (HR) }\end{array}$ \\
\hline
\end{tabular}




\section{Table 2: Basic Interview Protocol}

\begin{tabular}{llc}
\hline Focus & Question & Time, min \\
\hline Open reflection & $\begin{array}{l}\text { Think about the future and how your organization relates to it. Which different kinds } \\
\text { of time horizons are you working with? }\end{array}$ & 5 \\
Perspective & $\begin{array}{l}\text { Has the view on the future changed in the time you have been with the organization? } \\
\text { How? }\end{array}$ & 5 \\
Practices & $\begin{array}{l}\text { Think about a concrete strategy or situation where you really feel that you have } \\
\text { addressed future issues: Can you describe its main contents? Ilow did you identify the } \\
\text { future perspectives and how did you convert these to planned strategic action? }\end{array}$ & 5 \\
Practices & $\begin{array}{l}\text { How do you budget for the long-term future? What is different than your ongoing } \\
\text { yearly/3-year budgeting? }\end{array}$ & 2 \\
\hline Institutions/Structure & Does your organization exist in 200 years - and why? \\
Institutions/Practices & $\begin{array}{l}\text { Which large-scale societal problems do you see rising these next 200 years and do } \\
\text { you see your organization as part of the solution to some of these? Why/how? }\end{array}$ & 3 \\
\hline
\end{tabular}

